Research Article

\title{
Preparation of Silver Nanoparticles in a Plasma-Liquid System in the Presence of PVA: Antimicrobial, Catalytic, and Sensing Properties
}

\author{
Margarita I. Skiba $\mathbb{D}^{1}{ }^{1}$ Victoria I. Vorobyova ${ }^{\mathbb{D}},{ }^{2}$ and Iryna V. Kosogina $\mathbb{D}^{2}$ \\ ${ }^{1}$ Department of Inorganic Materials Technology and Ecology, Ukrainian State, University of Chemical Technology, \\ Dnipro 49005, Ukraine \\ ${ }^{2}$ Department of Physical Chemistry, National Technical University of Ukraine "Igor Sikorsky Kyiv Polytechnic Institute", \\ Kyiv 03056, Ukraine
}

Correspondence should be addressed to Margarita I. Skiba; margaritaskiba88@gmail.com

Received 20 February 2020; Revised 1 May 2020; Accepted 11 May 2020; Published 3 June 2020

Academic Editor: Honghong Wu

Copyright (c) 2020 Margarita I. Skiba et al. This is an open access article distributed under the Creative Commons Attribution License, which permits unrestricted use, distribution, and reproduction in any medium, provided the original work is properly cited.

\begin{abstract}
The preparation of stabilized silver nanodispersions under the action of short-term plasma discharge using a polyvinyl alcohol stabilizer (polyvinyl alcohol (PVA)) was investigated. The influence of the basic technological parameters such as initial $\mathrm{Ag}^{+}$ concentration, PVA concentration, and process duration on the formation of nanoparticles and their characteristics (size and stability) were determined. The UV-Vis spectra showed the localized surface plasmon resonance at wavelengths of 400-420 nm. The SEM images showed that the shape of Ag NPs is spherical with an average particle size up to $30 \mathrm{~nm}$. Ag NPs were used as a catalyst for the reduction of 4-nitrophenol (4-NP). The effect of the concentration of PNP and catalyst dosage on the value of apparent rate constant $\left(k_{\mathrm{app}}\right)$ for catalytic reduction of 4-NP in the presence of Ag NPs was investigated by means of UV-Vis spectrophotometry. The antimicrobial activity of Ag nanoparticles was investigated against yeast and Escherichia coli. The colorimetric sensor studies of plasma synthesized Ag NPs showed selective sensing of the potentially hazardous $\mathrm{Hg}^{2+}$ ion in water.
\end{abstract}

\section{Introduction}

The preparation and characterization of metal nanoparticles with different nomenclatures, structures, and properties are a major research area in various fundamental and practical fields: nanoscale science, engineering, ecology, water treatment, chemical industry, medicine, etc. $[1,2]$. According to the various assessments, silver nanodispersions are among the top 10 nanomaterials in the World Low-Tech Production $[3,4]$. Nowadays, numerous traditional and novel methodologies have been developed for the synthesis of Ag NPs $[1,2,5]$.

The analysis of the literature [1-8] shows that all known methods have advantages and disadvantages. As a rule, when carrying out the research, the authors use different physicochemical methods and obtain silver nanoparticles with specified properties. However, during the synthesis, the choice of reagents and process conditions is not standardized by ISO quality standards.

It is undeniable that the compliance of the nanomaterials with ISO quality standards is a very important parameter at all stages of their life cycle. In addition, it is also an important indicator for potential international customers [9].

According to the ISO standards, it is recommended to opt for technology with fewer reagents, "green" and more environmentally friendly resources. The preparation of the metal nanoparticles with the help of a green chemistry method must be evaluated under three specific aspects: the choice of nontoxic solvent, an environmentally friendly reducing agent, and a biodegradable stabilizing agent $[10,11]$. The method of obtaining silver nanoparticles under the action of plasma discharge corresponds to all three of 
them [11-13]. The plasma reduction has been proven to be a powerful tool to produce metallic nanoparticles. The metallic nanoparticles can be prepared in an aqueous solution in the presence of a stabilizer without using chemical reducing agents. There are various types of plasma discharge. There is no single classification to the present day. The short-term (up to 5 minutes) discharge of nonequilibrium low-temperature plasma is usually used for the formation of colloidal aqueous solutions of silver nanoparticles [14-16]. The authors have demonstrated the effectiveness of using CNP for the synthesis of silver nanoparticles in the presence of different types of stabilizers: sodium alginate [17], sodium citrate [18], etc $[19,20]$.

However, for the development of the omnipurpose plasma technology suitable for industrial implementation, it is advisable to study the patterns and characterization of the properties of silver nanoparticles obtained with different types of stabilizers.

Analysis of the literature [21-25] indicates that one of the widely used reagent stabilizers is polyvinyl alcohol (PVA). There are a considerable number of studies in which the use of PVA is investigated both as a stabilizer and as a stabilizerreducing agent.

Meanwhile, one major drawback of the abovementioned studies examining the use of PVA is the lack of research on the properties of the material obtained. As a rule, the authors demonstrate the already known antimicrobial properties $[7-9,26,27]$. Other important properties of silver NPs, such as catalytic ones, remain unaddressed. Research on the multifunctionality of silver NPs can be broadly used for purification and decontamination of both drinking water and wastewater from various industries.

The main goal is to determine the influence of the various conditions on the synthesis of silver nanoparticles in the presence of polyvinyl alcohol using low-temperature nonequilibrium contact plasma and on properties (antimicrobial, catalytical, and sensing) of the obtained Ag nanoparticles for the further implementation in various fields.

\section{Materials and Methods}

2.1. Materials. Silver nitrate (99.8\%, Kishida), polyvinyl alcohol $(\mathrm{Mw}=40$ 000) (PVA; hydrolysis degree of 99.0-99.8\%), and p-nitrophenol were purchased from Sigma-Aldrich, USA. Aqueous solutions of precursor were prepared using ultrapure water (Direct-Q UV, Millipore) and were utilized as starting materials without further purification.

2.2. Synthesis of Silver Nanoparticles (AgNPs). In a typical experiment, around $37.5 \mathrm{ml}$ of $\mathrm{AgNO}_{3}$ salt with a molarity of 0.3-3.0 $\mathrm{mmol} / \mathrm{L}$ was added dropwise to $2.5 \mathrm{ml}$ of PVA solution $(C=1.25 \mathrm{~g} / 1$ for $0.3 \mathrm{mmol} / \mathrm{L}, C=2.5 \mathrm{~g} / \mathrm{l}$ for $0.5 \mathrm{mmol} /$ $\mathrm{L}, C=2.5 \mathrm{~g} / \mathrm{l}$ for $1.0 \mathrm{mmol} / \mathrm{L}$, and $C=5.0 \mathrm{~g} / \mathrm{L}$ for $3.0 \mathrm{mmol} / \mathrm{L}$ $\mathrm{Ag}^{+}$). PVA solution was prepared by dissolving PVA powder in double-distilled water (at $85^{\circ} \mathrm{C}$ for $1 \mathrm{~h}$ ). The solution of $\mathrm{AgNO}_{3}$-PVA was in the reactor with the discharge of plasma. A detailed diagram of the installation and image of the plasma discharge is provided in the work $[28,29]$.

2.3. Characterization Techniques. The formation behaviour of Ag NPs in the PVA solution was examined by using a UVVis spectrophotometer (UV-5800PC) with a variable wavelength between 300 and $700 \mathrm{~nm}$ in 5-10 $\mathrm{nm}$ increments, using a $1 \mathrm{~cm}$ optical path at room temperature. In the study of kinetic dependencies, the amount of $\mathrm{Ag}^{+}$was reduced using the ion-selective electrode of $\mathrm{Ag}^{+}$ions (ELIS-131Ag).

Microphotographs of nanoparticles were obtained on the scanning electron microscope JEOL JSM-6510LV (JEOL, Tokyo, Japan). TEM micrograph of the sample was taken using the JEOL TEM (Model 100 CX II; Tokyo, Japan). The particle size distribution and zeta potential of the prepared Ag NPs colloid were determined by the DLS technique using the Zetasizer Nano-25 analyzer (Malvern Instruments Ltd., Malvern, England) within the range of $0.1-10000 \mathrm{~nm}$. The same instrument was also used to measure electrophoretic mobility which was subsequently transformed to $\zeta$-potential using Smoluchowski's approximation. The value of the hydrogen index of the original solutions and the obtained sols was measured using a $\mathrm{pH}$ meter $\mathrm{pH}-150 \mathrm{MI}$ (relative measurement error of $0.5 \%$ ).

2.4. Antimicrobial Activity Test. The suspension method is used to determine the antimicrobial activity of the obtained dispersions against test microorganisms. The preparation of work dilutions of nanosilver was carried out using a buffer solution of $\mathrm{pH}$ 7.0. E. coli at a concentration of $104 \mathrm{CFU} / \mathrm{cm}^{3}$ was used as the test microorganism to determine the antimicrobial action of the colloidal nanosilver solution. The duration of the exposure in the experiment was $5 \mathrm{~min}, 1$ hour, 2 hours, and 3 hours. During the test, $0.1 \mathrm{~cm}^{3}$ suspension of the test microorganisms was added to $5 \mathrm{~cm}^{3}$ of each mixture of work dilutions. Samples with solutions were incubated at $(20 \pm 1)^{\circ} \mathrm{C}$. At the end of the exposure time, the samples were seeded at $0.5 \mathrm{~cm}^{3}$ into two Petri dishes with a dense nutrient medium of TSA, which were incubated at $36^{\circ} \mathrm{C}$ for 24 hours. The amount of $\mathrm{CFU} / \mathrm{cm}^{3}$ was calculated for each dilution. The test results of the colloidal solution of nanosilver were compared with the results of E. coli culture control, carried out similar to the experiment.

2.5. Catalytic Activity. Separate catalytic degradation experiments were performed for the aqueous azo dyes, namely, $\mathrm{MB}$ and for 4- nitrophenol. As a model reaction, we selected the reduction of 4-NP to 4-AP by $\mathrm{NaBH}_{4} \cdot \mathrm{NaBH}_{4}$ is known to stimulate catalytic reduction of $\mathrm{p}-\mathrm{NP}$ by cleavage of the $\mathrm{N}-\mathrm{O}$ bond for replacement with an $\mathrm{N}-\mathrm{H}$ bond in an aqueous environment. The catalytic hydrogenation of PNP to PAP was carried out in a $50 \mathrm{~mL}$ beaker with a PNP aqueous solution $(20 \mathrm{~mL}, 0.1 \mathrm{mM})$. Then, $2 \mathrm{~mL}$ of freshly prepared aqueous solution of $\mathrm{NaBH}_{4}(0.2 \mathrm{M})$ was introduced into the above solution. Subsequently, $2 \mathrm{~mL}(3.0 \mathrm{mmol} / \mathrm{L})$ of catalyst was added to the solution with magnetic stirring at room temperature $\left(25^{\circ} \mathrm{C}\right)$. The intensity of the absorption peak at 
$400 \mathrm{~nm}$ in the UV-Vis spectrophotometer was used to monitor the process of the conversion of $\mathrm{p}$-nitro phenol ( $\mathrm{p}$ $\mathrm{NP}$ ) to p-aminophenol ( $\mathrm{p}-\mathrm{AP})$.

2.6. Colorimetric Detection. AgNPs were evaluated as a colorimetric sensor for various metal ions by adding a uniform concentration $\left(0.5 \mathrm{~mL}, 10^{-3} \mathrm{M}\right)$ of metal salt solutions $\left(\mathrm{Hg}^{2+}\right)$ into a prepared Ag NPs solution $(3 \mathrm{~mL})$. Then, the absorption spectra were obtained during $10 \mathrm{~min}$, and color changes were observed by the naked eye.

\section{Results and Discussion}

In previous studies, it has been claimed that the presence of a stabilizer reagent is obligatory for the formation of stable silver dispersions under the action of a plasma discharge. Plasma compounds are formed in a solution during the action of a plasma discharge. Previous numerical studies have shown that the duration of the discharge up to 5-7 minutes is sufficient to form nanoparticles in a discrete-type reactor (plasma parameters: pressure at $80 \mathrm{kPa}$, current strength at $120 \mathrm{~mA}$, distance from the electrode to the surface was $5-7 \mathrm{~mm}$, and the material of electrodes was $\mathrm{X} 18 \mathrm{H} 10 \mathrm{~T})$.

For the unification of this assertion, similar studies have been performed for aqueous solutions with a PVA stabilizer.

Figure 1 shows the dependence of the spectrum of the obtained silver NPs on the duration of action of the plasma discharge on the initial solution of silver nitrate $(0.3-3.0 \mathrm{mmol} / \mathrm{l})$ at molar ratios of $\left[\mathrm{Ag}^{+}\right]:[\mathrm{PVA}]=(1)$ : ( 0.0055) for $0.3-0.5 \mathrm{mmol} / \mathrm{l}$, (1):( 0.003) for $1.0 \mathrm{mmol} / \mathrm{l}$, and (1):( 0.002) for $3.00 \mathrm{mmol} / \mathrm{l})$ in the presence of PVA. A dark brown suspension of colloids was formed after the plasma treatment of the reaction mixture from $10 \mathrm{sec}$ up to $7 \mathrm{~min}$. This dark brown color may be due to the collective vibrations of the charged particles present on the surface of nanoparticles and the resonance.

The analysis of the obtained data has led to a number of conclusions as follows:

In all studied samples (when changing the ratio $\mathrm{Ag}^{+}$/ PVA), with increase in the duration of the discharge of plasma, there is an increase in the intensity of absorption. The SPR peak is observed in the range of $410-450 \mathrm{~nm}$, which is typical for nanoparticles up to $30 \mathrm{~nm}$ in size. This value is in good correlation with the literature $[1-27,30]$ reports on the spectrum of silver nanoparticles in aqueous solutions. However, the presence of only one absorption peak confirms the spherical shape of the NPs being studied. As for the absorption spectrum of unirradiated pure PVA, it has shown near zero absorption.

In all tested samples, the maximum optical density was reached in 4-6 minutes; however, in the case of a silver concentration of $3.0 \mathrm{mmol} / \mathrm{L}$, the treatment duration of the discharge of 6-7 min contributes to a broad peak, which indicates the formation of nanoparticles with a high index of dispersion.

In the previous work [31], it was shown that the formation of silver nanoparticles without the introduction of the stabilizer reagent is a pseudo-first-order reaction and the reaction rate constant is $0.4 \mathrm{~min}^{-1}$. Investigation of the kinetics of nanoparticle dispersion formation with the addition of PVA also showed that the reaction is pseudo-first order. However, the reaction rate constant is slightly higher and is $\sim 0.55 \mathrm{~min}^{-1}$ (Figure 2). Such a slight increase in the constant value is likely to be associated with the possible reducing properties of $\mathrm{Ag}^{+}$ions, in addition to their stabilizing ability.

It is known that the properties of nanosystems depend on the size characteristics of the nanoparticles. Therefore, controlling their morphology and size is an important task. The synthesis conditions directly affect the size and shape of the nanoparticles and their polydispersity.

For the investigated ratios of the reagents, the average particle size and stability of the obtained colloidal dispersions have been established (Table 1, Figure 3). Depending on the $\mathrm{Ag}^{+}$/PVA ratio, the solutions obtained are characterized by an average zeta potential within the range of -37.6 to $-39.7 \mathrm{mV}$ which indicates the high stability of the prepared Ag NPs. In addition, the measurement of the optical absorption spectrum of a colloidal NP solution over a long period (6 months) revealed no significant changes in the spectrum, indicating the stability of the NPs. The average particle size was found to be $25-30 \mathrm{~nm}$.

Morphological investigation of $\mathrm{Ag} / \mathrm{PVA}$ NPs is carried out using SEM and TEM (Figure 4).

The nanoparticles have a spherical shape. Figure 4 shows that the average size is smaller than the measurement method (DLS). The larger average diameter measured may be a result of the following: the adsorption of the PVA on a cluster of particles rather than on individual particles or sonication may have not fully dispersed the aggregated particles, thus resulting in larger average diameter values of the SEM measurements.

Previous studies have shown that using a stabilizer of steric type (sodium alginate) and plasma-chemical synthesis of adjusting the $\mathrm{pH}$ of the solution to an alkaline environment (more than 8) is desirable, as it leads to an increase in the average particle size and size distribution. Furthermore, it is known from the other studies that changes in solution $\mathrm{pH}(2-10)$ had no effect on $\zeta$-potential of the sterically stabilized Ag NPs.

The initial value of the solutions' $\mathrm{pH}$ is 6.33-7.03, depending on the initial silver ions and PVA (Figure 5). The nature of the dependence coincides with one another, and a sharp decrease in $\mathrm{pH}$ to 3.5 is seen after 40 seconds of the effect of the discharge on the solution.

The modified suspension method was the optimal method for determining the antimicrobial activity of silver NP solutions [32]. The advantage of the latter in comparison with the studied method of dilutions and the method of diffusion in agar is the use of distilled water as a solvent, which minimizes inactivation of nanoparticles.

Experimental studies to determine the antimicrobial activity of a colloidal nanoparticle solution has shown that the $E$. coli test microorganism is sensitive to the action of $\mathrm{Ag}$ nanoparticles at concentrations of 20 to $12 \mu \mathrm{g} / \mathrm{cm}^{3}$ (Table 2). Therefore, at the presence $20.0 \mu \mathrm{g} / \mathrm{cm} 3 \mathrm{Ag}$ NPs in the 

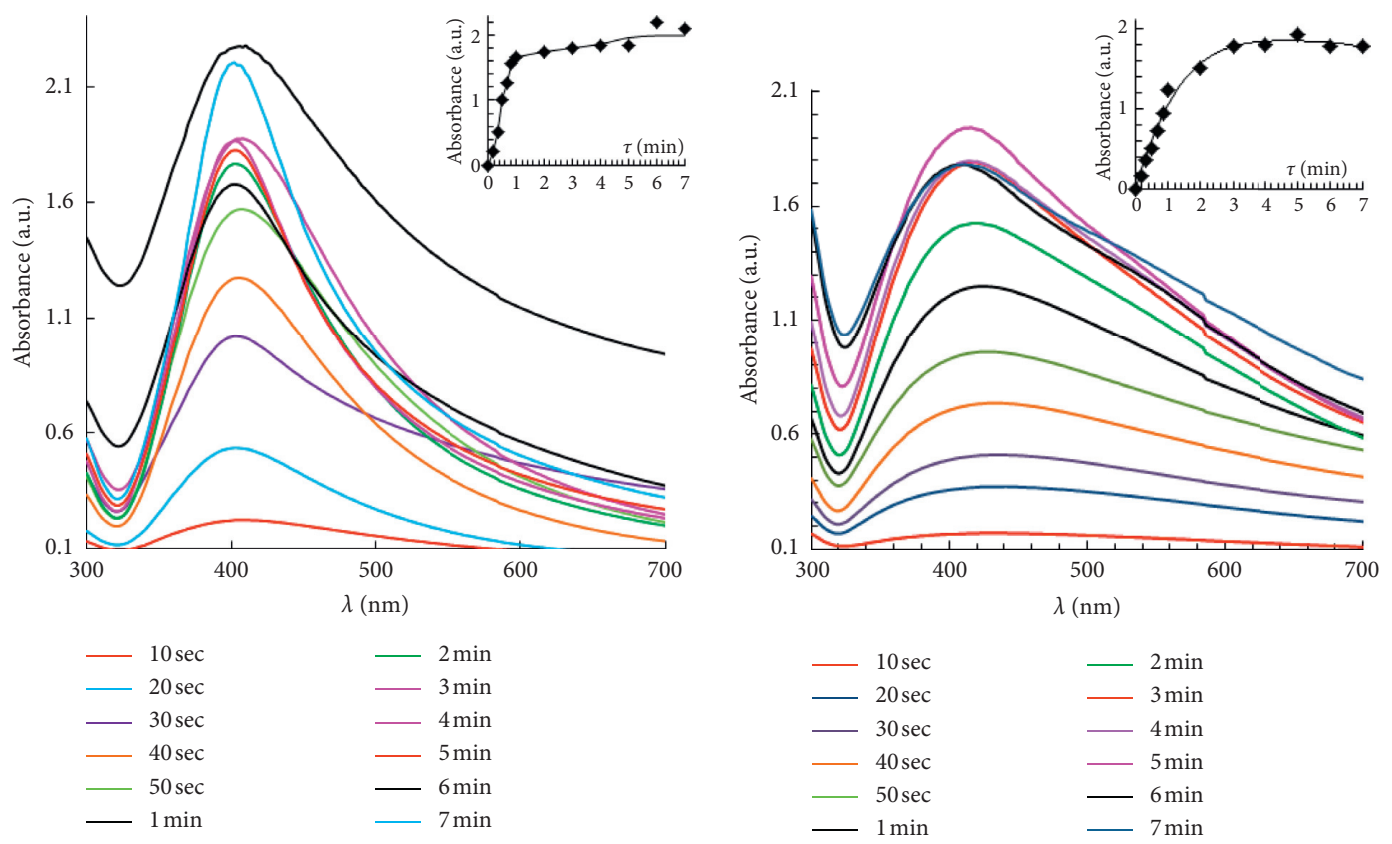

(a)

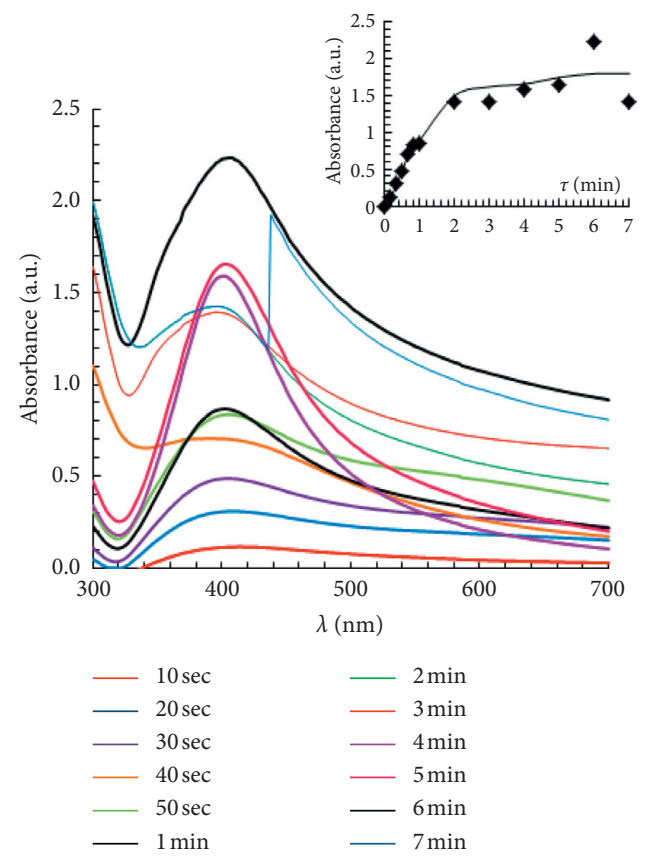

(c)

(b)

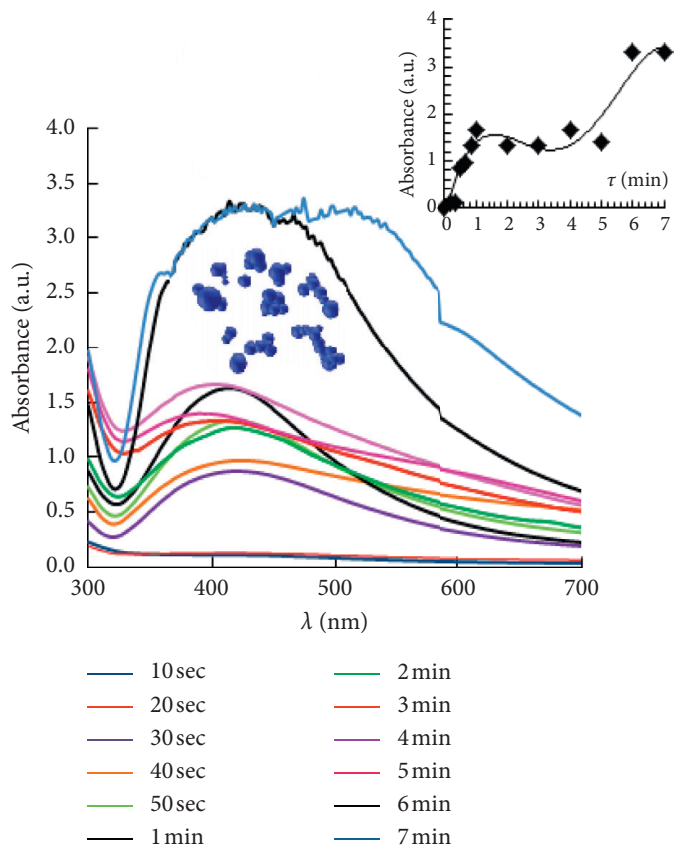

(d)

Figure 1: Absorption spectrums of silver nanodispersions with the addition of stabilizer,PVA, at different concentrations of Ag ${ }^{+}: 0.3 \mathrm{mmol} /$ 1 (molar ratio $\left[\mathrm{Ag}^{+}\right]:[\mathrm{PVA}]=(1):(\sim 0.0055)(\mathrm{a}), 0.5 \mathrm{mmol} / 1\left[\mathrm{Ag}^{+}\right]:[\mathrm{PVA}]=(1):(\sim 0.0055)(\mathrm{b}), 1.0 \mathrm{mmol} / 1\left(\left[\mathrm{Ag}^{+}\right]:[\mathrm{PVA}]=(1):(\sim 0.003)(\mathrm{c})\right.$, and $\left.3.0 \mathrm{mmol} / \mathrm{l}\left[\mathrm{Ag}^{+}\right]:[\mathrm{PVA}]=(1):(\sim 0.002)(\mathrm{d})\right)$.

samples with fixed amount colony-forming unit (CFU) after 5 min exposition is not observed CFU. In the presence 12.0 $\mu \mathrm{g} / \mathrm{cm} 3 \mathrm{Ag}$ NPs time for antibacterial effect more then $5 \mathrm{~min}$ and is about 3 hours. Exposure within 3 hours has caused a bactericidal effect on the test microorganisms. At concentrations of $3.75 \mu \mathrm{g} / \mathrm{cm}^{3}$ and $1.875 \mu \mathrm{g} / \mathrm{cm}^{3}$, a steady decrease in microbial load has occurred during this time. It should be noted that antibacterial studies need further investigation by other known methods.

Phenol and its derivatives are highly stable organic compounds and very hazardous to the environment. Every year, the countries in the world produce thousands of tons of nitrophenols. These compounds are very toxic to aquatic organisms and can cause direct neurotoxicity. 


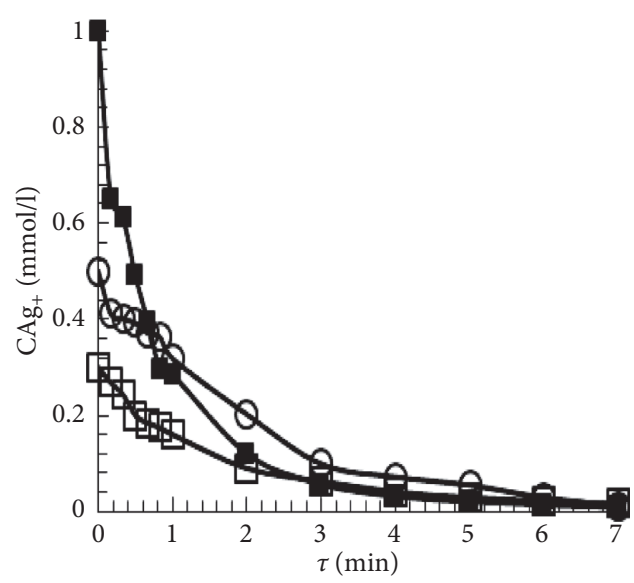

(a)

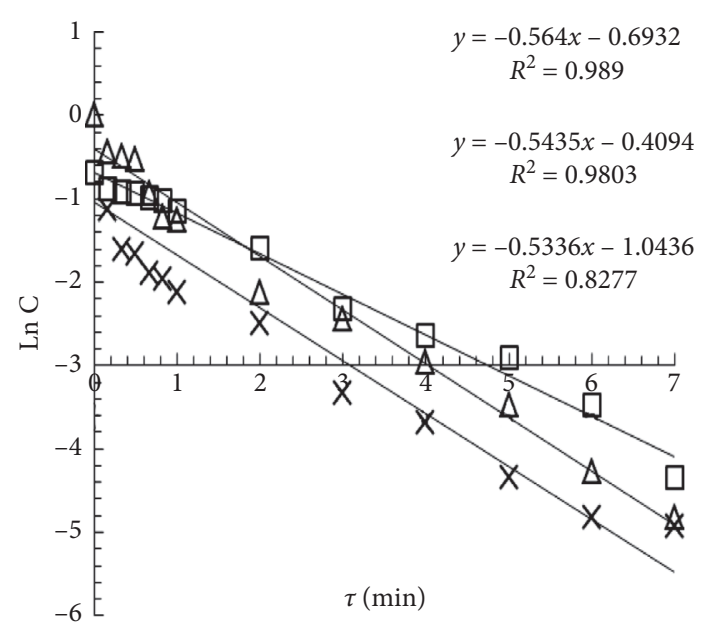

(b)

Figure 2: Dependence of equilibrium $\mathrm{Ag}^{+}$concentration and logarithm as a function of the duration of plasma discharge at different initial concentrations of silver ions in solution in the presence of PVA.

TABLE 1: Size of silver nanoparticles obtained under the conditions of plasma treatment $\left(\mathrm{Ag}^{+} / \mathrm{PVA}\right)$ solution $(\tau=5 \mathrm{~min})$.

\begin{tabular}{lcc}
\hline $\mathrm{C} \mathrm{AgNO}_{3}(\mathrm{mmol} / \mathrm{L})$ & Z-potential $(\mathrm{mV})$ & Average particle size $(d)$ of AgNPs $(\mathrm{nm})$ \\
\hline 0.3 & -37.6 & 30.1 \\
0.5 & -38.1 & 31.1 \\
1.0 & -39.7 & 33.0 \\
\hline
\end{tabular}

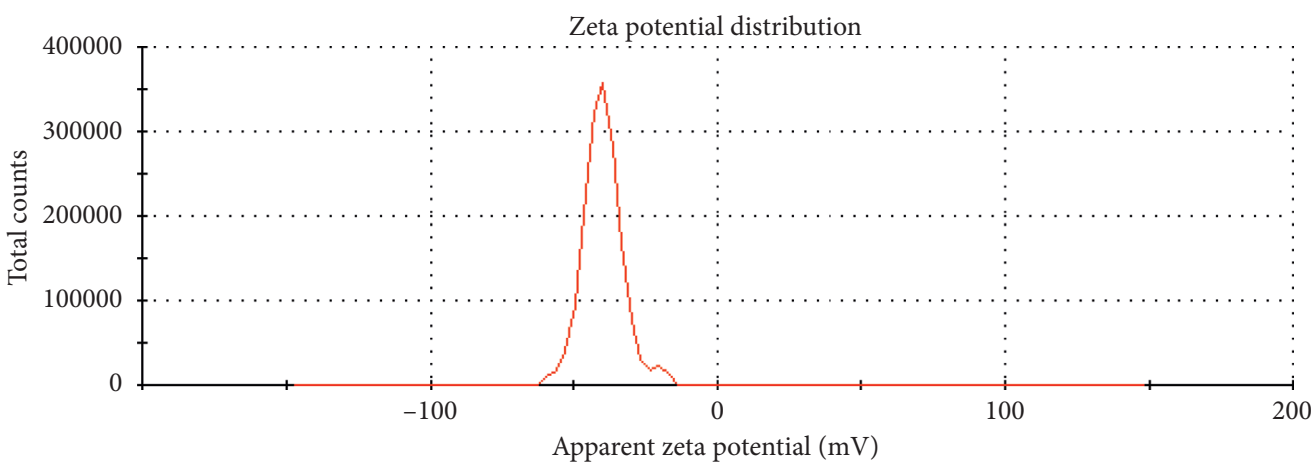

Record 16: Ag 31

\begin{tabular}{|c|c|c|c|c|}
\hline & & Mean $(\mathrm{mV})$ & Area (\%) & St Dev $(\mathrm{mV})$ \\
\hline Zeta potential $(\mathrm{mV}):-39.7$ & Peak 1: & -40.2 & 96.9 & 6.23 \\
\hline Zeta deviation $(\mathrm{mV}): 6.88$ & Peak 2: & -20.5 & 3.1 & 2.43 \\
\hline Conductivity $(\mathrm{mS} / \mathrm{cm}): 0.475$ & Peak 3: & 0.00 & 0.0 & 0.00 \\
\hline Result quality: Good & & & & \\
\hline
\end{tabular}

FIgure 3: Zeta potential of water colloid silver/PVA (C $\mathrm{AgNO}_{3} 1.0 \mathrm{mmol} / \mathrm{L}$ for $\left.5 \mathrm{~min}\right)$.

It is known that the original 4-nitrophenol (4-NP) aqueous solution with light yellow color shows an absorption peak centered at $317 \mathrm{~nm}$ [29]. After adding $\mathrm{NaBH}_{4}$ solution, the maximum absorption shifted to $400-410 \mathrm{~nm}$, with a simultaneous color change to bright yellow due to the formation of p-nitrophenolate ions under the alkaline condition (Figure 5).
In the presence of a catalyst (Ag NPs), the peak at $410 \mathrm{~nm}$ decreases over time and is accompanied by the formation of a new peak at $298 \mathrm{~nm}$. Such changes characterize the reduction of nitrophenol to 4-aminophenol (4-AP).

The linear correlation between $\ln \left(A_{t} / A_{0}\right)$ versus reduction time in minutes indicates that the reduction follows a pseudo- 


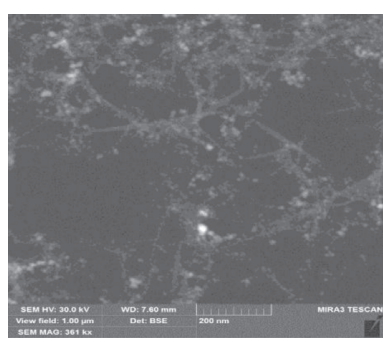

(a)

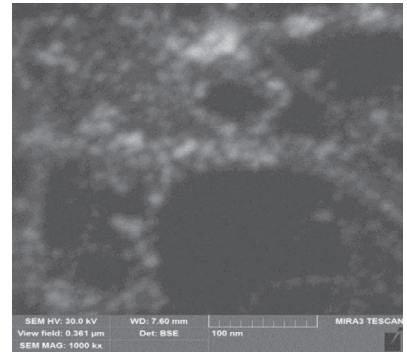

(d)

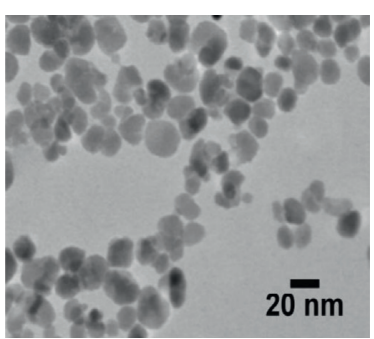

(b)

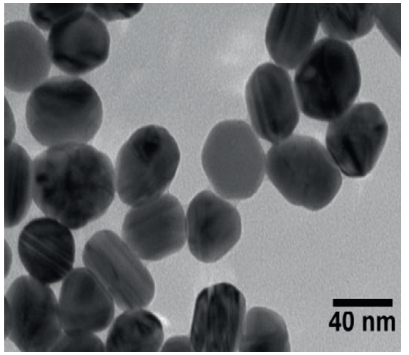

(e)

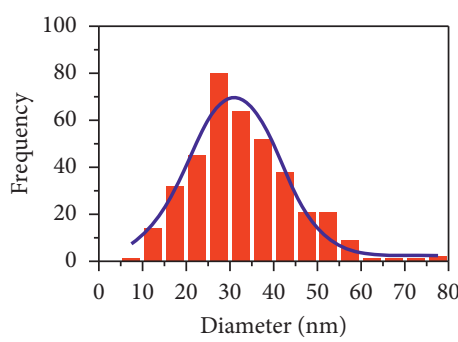

(c)

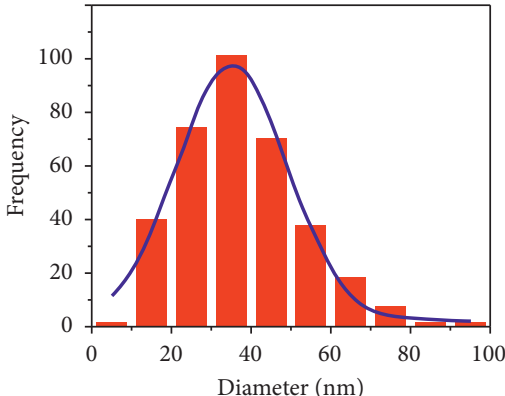

(f)

FIGURE 4: SEM and TEM images of silver nanoparticles obtained by plasma treatment in the presence of PVA and corresponding size distribution of AgNPs $\left(\mathrm{C} \mathrm{AgNO}_{3} 0.3\right.$ and $\left.1.0 \mathrm{mmol} / \mathrm{L}, \tau=5 \mathrm{~min}\right)$.

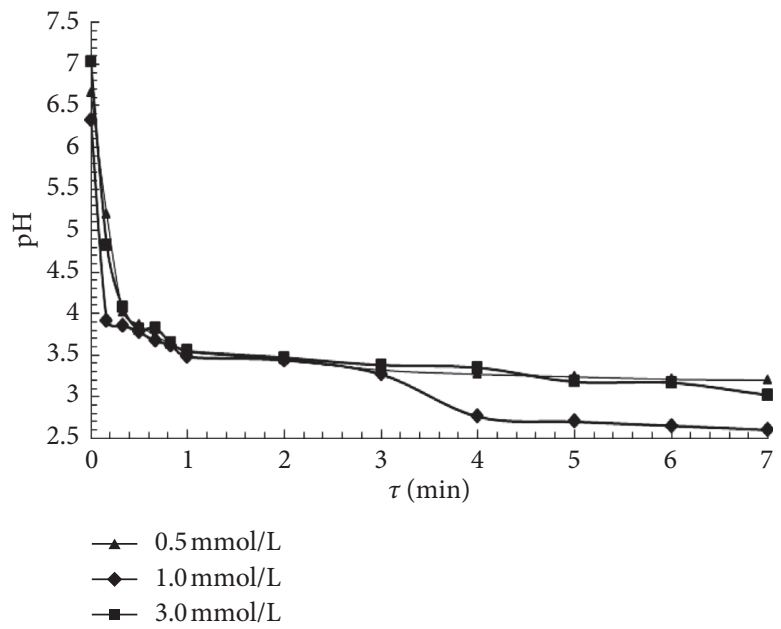

FIGURE 5: Change in the $\mathrm{pH}$ of the solution during the plasma treatment and formation of silver nanoparticles.

TABLE 2: Determination of the antimicrobial activity of a solution of nanoparticles against the test microorganism E. coli with the help of the suspension method.

\begin{tabular}{lcccccc}
\hline \multirow{2}{*}{ Exposure time } & \multicolumn{4}{c}{ Concentration of silver NPs $\left(\mu \mathrm{g} / \mathrm{cm}^{3}\right), \mathrm{CFU} / \mathrm{cm}^{3}$} & Test microorganism E. coli \\
& 20.0 & 12.0 & 5.5 & 3.75 & 1.875 & 65 \\
5 min & 0 & 25 & 28 & 26 & 52 & 61 \\
1 hour & 0 & 15 & 27 & 30 & 33 & 62 \\
2 hours & 0 & 13 & 24 & 18 & 19 & 63 \\
3 hours & 0 & 0 & 6 & 10 & 12 & \\
\hline
\end{tabular}




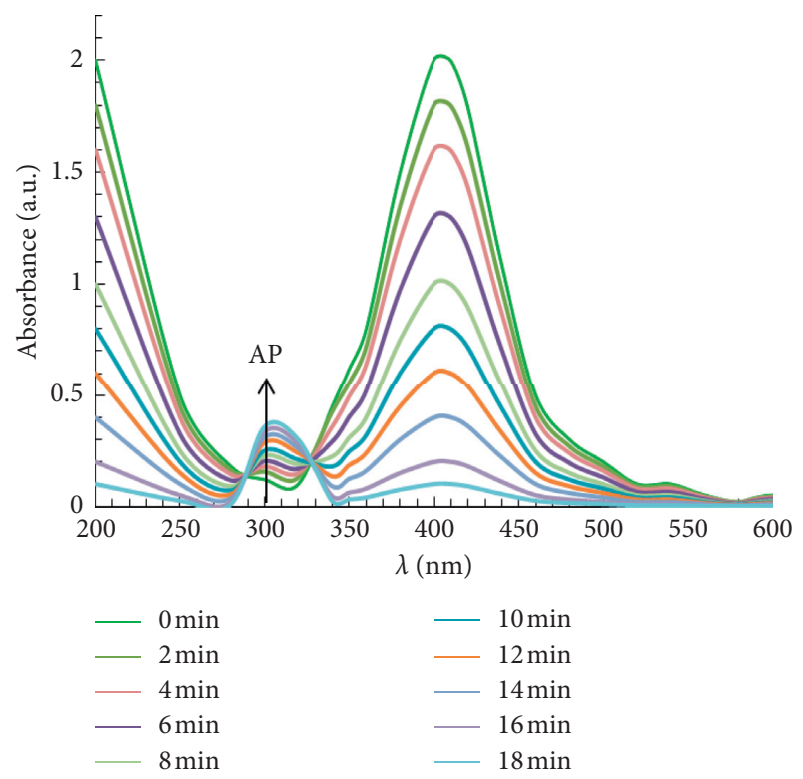

(a)

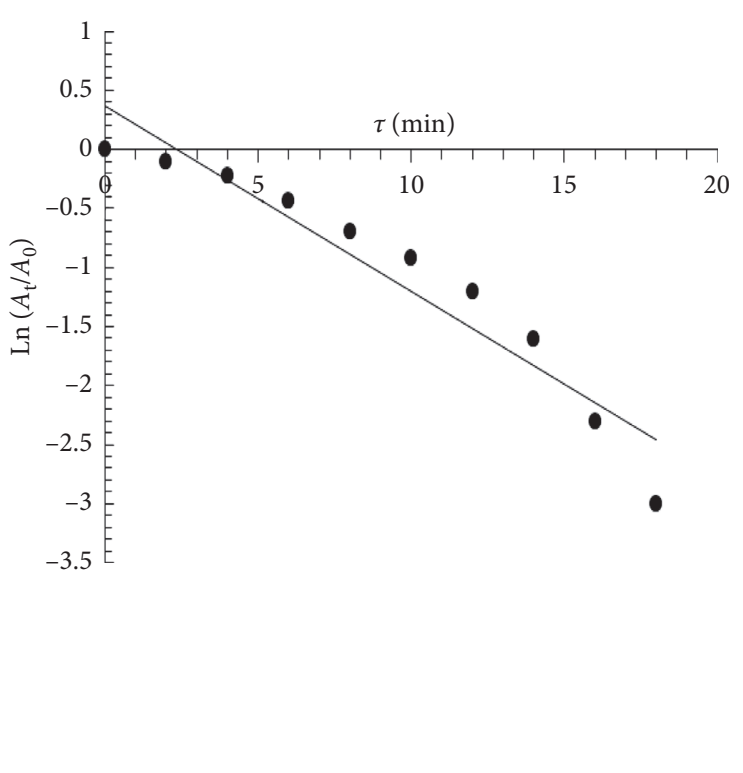

(b)

Figure 6: Catalytic reduction of 4-nitrophenol (4-NP) to 4-aminophenol (4-AP) with the Ag NPs as the nanocatalyst (a); ln $\left(A / A_{0}\right)$ versus reaction time (b).

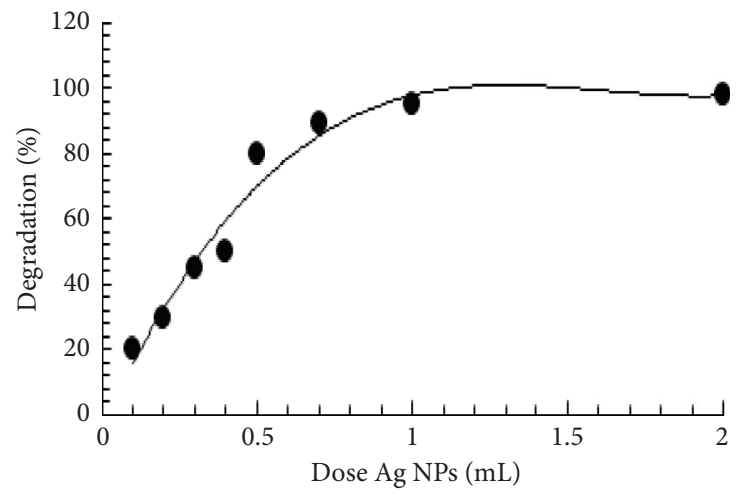

(a)

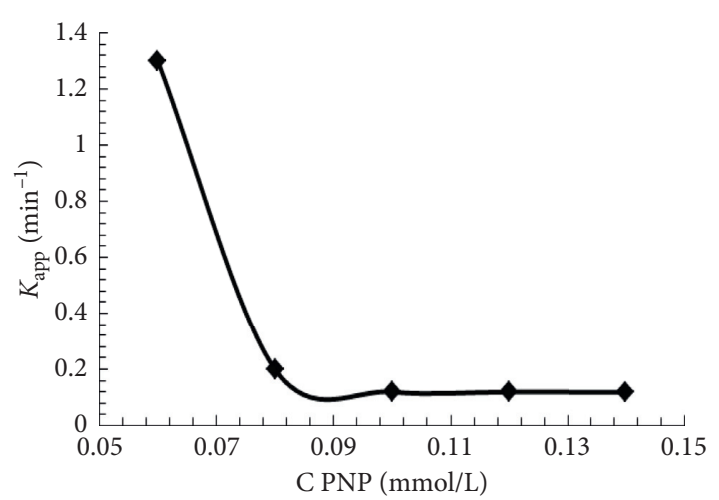

(b)

FIGURE 7: Effects of catalyst dosage (a) and concentration of PNP (b) on the catalytic performances.

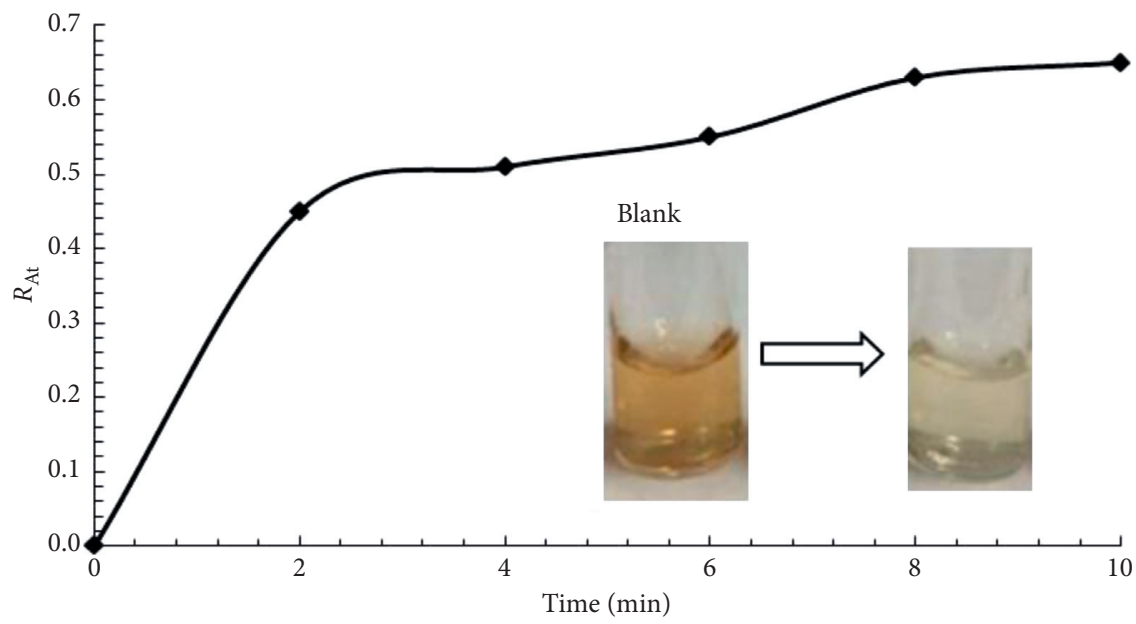

FIgURE 8: Relative change in absorbance, $R_{\mathrm{At}}$, as a function of time at a fixed concentration of $\mathrm{Hg}^{2+}$. 
first-order reaction kinetics (Figure 6(b)) $\left(K_{\text {app }}=\ln A / A_{0}=\ln\right.$, where $A$ and $A_{0}$ are the peak absorbances of $4-\mathrm{NP}$ at $400 \mathrm{~nm}$ at a given time $t$ and initial time $(t=0) ; K_{\text {app }}$ is the apparent rate constant $\left(\sim 0,17 \mathrm{~min}^{-1}\left(R^{2}=0.98\right)\right)$.

The effect of the catalyst dose on the decomposition of the pollutant was investigated. Figure 7 (a) shows that an increase in the amount of Ag leads to an increase in the rate of decomposition. Therefore, the introduction of 0.5 to $2 \mathrm{ml}$ per $20 \mathrm{ml}$ of solution into the reaction medium allows us to obtain rates of destruction of nitrophenol at the level of $80-98 \%$. This is because more catalytic active sites can be provided with more catalyst being added into the reaction mixture. Figure 7(b) shows that the increase of the PNP concentration results in a decrease of the $K_{\text {app }}$ value.

There is evidence of the detection of metal ions using spherical silver nanoparticles. The use of silver nanoparticles for determination of $\mathrm{Hg}$ has been described [33]. In most cases, the determination is based on the formation of ionic and/or coordination bonds between metal ions and nanoparticle modifiers; therefore, the type of modifier plays an important role in regulating the sensitivity and selectivity of the determination. Due to the interaction of a metal ion with modifier molecules located on the surface of silver NPs, most often "crosslinking" of nanoparticles occurs, which leads to their aggregation, which is accompanied by a strong change in the optical characteristics of the system.

It was found (Figure 8) that the addition of $\mathrm{Hg}^{2+}$ solution into Ag NPs decolorized the solution from dark yellow and demonstrated the selective sensing of $\mathrm{Hg}^{2+}$ ions.

\section{Conclusions}

In the present study, the synthesis of silver NPs has been demonstrated by a green and environmentally friendly approach using short-term plasma discharge and polyvinyl alcohol as a stabilizer agent. The influence of the basic technological parameters such as initial $\mathrm{Ag}^{+}$concentration, PVA concentration, and process duration on the formation of nanoparticles and their characteristics (size and stability) was determined. The effect of the concentration of PNP and catalyst dosage on the value of apparent rate constant $\left(k_{\mathrm{app}}\right)$ for catalytic reduction of 4-NP in the presence of Ag NPs was investigated by means of UV-Vis spectrophotometry. The antimicrobial activity of Ag nanoparticles was investigated against yeast and Escherichia coli. We tested Ag NPs as plasmonic sensors in water. The colorimetric sensor studies of plasma-synthesized AgNPs showed selective sensing of the potentially hazardous $\mathrm{Hg}^{2+}$ ion in water.

\section{Data Availability}

All data are provided in the Results section of this paper. The data used to support the findings of this study (SEM images) are included within the article and are available from the corresponding author upon reasonable request.

\section{Conflicts of Interest}

The authors declare that they have no conflicts of interest.

\section{Acknowledgments}

This work was supported by a grant of the Ministry of Education and Science of Ukraine (grant no. 2044, 2019-2021) and a program of the European Union (Harmonising Water-Related Graduate Education/WaterH (http://www.waterh.net)).

\section{References}

[1] Y. Ju-Nam and J. R. Lead, "Manufactured nanoparticles: an overview of their chemistry, interactions and potential environmental implications," Science of the Total Environment, vol. 400, no. 1-3, pp. 396-414, 2008.

[2] T. Quang Huy, N. van Quy, and L. Anh-Tuan, "Silver nanoparticles: synthesis, properties, toxicology, applications and perspectives," Advances in Natural Sciences: Nanoscience and Nanotechnology, vol. 4, no. 3, Article ID 033001, 2013.

[3] J. Pulit-Prociak and M. Banach, "Silver nanoparticles-a material of the future?" Open Chemistry, vol. 14, no. 1, pp. 76-91, 2016.

[4] N. Z. Janković and D. L. Plata, "Engineered nanomaterials in the context of global element cycles," Environmental Science: Nano, vol. 6, no. 2, pp. 2697-2711, 2019.

[5] X.-F. Zhang, Z.-G. Liu, W. Shen, and S. Gurunathan, "Silver nanoparticles: Synthesis, characterization, properties, applications, and therapeutic approaches," International Journal of Molecular Sciences, vol. 17, no. 9, p. 1534, 2016.

[6] S. M. Hosseinpour-Mashkani and M. Ramezani, "Silver and silver oxide nanoparticles: Synthesis and characterization by thermal decomposition," Materials Letters, vol. 130, pp. 259-262, 2014.

[7] Z. Ni, X. Gu, Y. He et al., "Synthesis of silver nanoparticledecorated hydroxyapatite (HA@Ag) poriferous nanocomposites and the study of their antibacterial activities," RSC Advances, vol. 8, no. 73, pp. 41722-41730, 2018.

[8] Y. Wu, Y. Yang, Z. Zhang, Z. Wang, Y. Zhao, and L. Sun, "A Facile Method to Prepare Size-tunable Silver Nanoparticles and Its Antibacterial Mechanism," Advanced Powder Technology, vol. 29, no. 2, pp. 407-415, 2018.

[9] S.P. Goutam, G. Saxena, D. Roy, A. K. Yadav, and R. N. Bharagava, "Green Synthesis of Nanoparticles and Their Applications in Water and Wastewater Treatment, Bioremediation of Industrial Waste for Environmental Safety," in Bioremediation of Industrial Waste for Environmental Safety, G. Saxena and R. Bharagava, Eds., pp. 349-379, Springer, Berlin, Germany, 2020.

[10] O. Długosz, K. Szostak, A. Staroń, J. Pulit-Prociak, and M. Banach, "Methods for Reducing the Toxicity of Metal and Metal Oxide NPs as Biomedicine," Materials, vol. 13, p. 279, 2020.

[11] T. Mineta, T. Saito, T. Yoshihara, and H. Sato, "Preparation of Silver Nanoparticles by Arc Plasma Method and Their Properties," Materials Transactions, vol. 60, no. 4, pp. 569573, 2019.

[12] P. Pohl, "Plasma-Based Synthesis and Modification of Nanomaterials,” Nanomaterials, vol. 9, no. 2, p. 278, 2019.

[13] G. Saito and T. Akiyama, "Nanomaterial Synthesis Using Plasma Generation in Liquid," Journal of Nanomaterials, vol. 2015, Article ID 123696, 21 pages, 2015.

[14] M. Skiba, A. Pivovarov, A. Makarova, O. Pasenko, A. Khlopytskyi, and V. Vorobyova, "Plasma-chemical formation of silver nanodispersion in water solutions," Eastern- 
European Journal of Enterprise Technologies, vol. 6, no. 90, pp. 59-65, 2017.

[15] M. Skiba, A. Pivovarov, V. Vorobyova, T. Derkach, and I. Kurmakova, "Plasma-chemical formation of silver nanoparticles: The silver ions concentration effect on the particle size and their antimicrobial properties," Journal of Chemical Technology and Metallurgy, vol. 54, no. 2, pp. 311-318, 2019.

[16] M. Skiba, A. Pivovarov, A. Makarova, and V. Vorobyova, "Plasmochemical preparation of silver nanoparticles: thermodynamics and kinetics analysis of the process," EasternEuropean Journal of Enterprise Technologies, vol. 2, no. 6, pp. 4-9, 2018.

[17] O.A. Pivovarov, M.I. Skiba, A.K. Makarova, V.I. Vorobyova, and O.O. Pasenko, "Plasma-chemical obtaining of silver nanoparticles in the presence of sodium alginate," Voprosy khimii i khimicheskoi tekhnologii, vol. 6, pp. 82-88, 2017.

[18] M. I. Skiba, A. A. Pivovarov, A. K. Makarova, and V I. Vorobyova, "Plasma-chemical synthesis of silver nanoparticles in the presence of citrate," Chemistry Journal of Moldova, vol. 13, no. 1, pp. 7-14, 2018.

[19] M. I. Skiba and V. Vorobyova, "The plasma-chemical formation of polysorbate 80-coated silver nanoparticles and composite materials for water treatment," Pigment \& Resin Technology, vol. 48, no. 5, pp. 431-438, 2019.

[20] O.A. Pivovarov, M.I. Skiba, A.K. Makarova, and V.I. Vorobyova, "One-pot synthesis of silver nanoparticles using nonequilibrium low temperature plasma in the presence of polyvinyl alcohol," Voprosy khimii i khimicheskoi tekhnologii, vol. 3, pp. 113-120, 2018.

[21] P. Sagitha, K. Sarada, and K. Muraleedharan, "One-pot synthesis of poly vinyl alcohol (PVA) supported silver nanoparticles and its efficiency in catalytic reduction of methylene blue," Transactions of Nonferrous Metals Society of China, vol. 26, no. 10, pp. 2693-2700, 2016.

[22] G. I. Dzhardimalieva and I. E. Uflyand, "Preparation of metalpolymer nanocomposites by chemical reduction of metal ions: functions of polymer matrices," Journal of Polymer Research, vol. 25, no. 12, 2018.

[23] J. Y. Cheon, Y. O. Kang, and W. H. Park, "Formation of Ag nanoparticles in PVA solution and catalytic activity of their electrospun PVA nanofibers," Fibers and Polymers, vol. 16, no. 4, pp. 840-849, 2015.

[24] A. Kumar, T. Behl, and S. Chadha, "Synthesis of physically crosslinked PVA/Chitosan loaded silver nanoparticles hydrogels with tunable mechanical properties and antibacterial effects," International Journal of Biological Macromolecules, vol. 149, pp. 1262-1274, 2020.

[25] Z. Zhang, Y. Wu, Z. Wang, X. Zhang, Y. Zhao, and L. Sun, "Electrospinning of Ag Nanowires/polyvinyl alcohol hybrid nanofibers for their antibacterial properties," Materials Science and Engineering: C, vol. 78, pp. 706-714, 2017.

[26] K. B. Narayanan, H. H. Park, and N. Sakthivel, "Extracellular synthesis of mycogenic silver nanoparticles by Cylindrocladium floridanum and its homogeneous catalytic degradation of 4-nitrophenol," Spectrochimica Acta Part A: Molecular and Biomolecular Spectroscopy, vol. 116, pp. 485-490, 2013.

[27] P. Cyganowski, D. Jermakowicz-Bartkowiak, A. Lesniewicz, P. Pohl, and A. Dzimitrowicz, "Highly efficient and convenient nanocomposite catalysts produced using in-situ approach for decomposition of 4-nitrophenol," Colloids and Surfaces A: Physicochemical and Engineering Aspects, vol. 590, p. 124452, 2020.

[28] M. Skiba, V. Vorobyova, A. Pivovarov, A. Shakun, E. Gnatko, and I. Trus, "“Green” synthesis of nanoparticles of precious metals: antimicrobial and catalytic properties," Eastern-European Journal of Enterprise Technologies, vol. 5, no. 6, pp. 51-58, 2018.

[29] M. Skiba and V. Vorobyova, "Green synthesis of silver nanoparticles using grape pomace extract prepared by plasma-chemical assisted extraction method," Molecular Crystals and Liquid Crystals, vol. 671, no. 1, pp. 142-151, 2018.

[30] M. Sabzi, M. J. Afshari, M. Babaahmadi, and N. Shafagh, "pHdependent Swelling and Antibiotic Release from Citric Acid Crosslinked Poly (vinyl alcohol) (PVA)/Nano Silver Hydrogels," Colloids and Surfaces B: Biointerfaces, vol. 188, 2019.

[31] M. I. Skiba, V. I. Vorobyova, O. A. Pivovarov, and N. P. Makarshenko, "Green synthesis of silver nanoparticles in the presence of polysaccharide: Optimization and characterization," Journal of Nanomaterials, vol. 2020, Article ID 3051308, 7 pages, 2020.

[32] L. Heijnen and G. Medema, "Quantitative detection of E. coli, E. coli O157 and other shiga toxin producing E. coli in water samples using a culture method combined with real-time PCR," Journal of Water and Health, vol. 4, no. 4, pp. 487-498, 2006.

[33] Y. Xue, L. Ma, L. Zhang, W. Zhao, Z. Li, and Q. Li, “A Green, Rapid and Efficient Dual-Sensors for Highly Selective and Sensitive Detection of Cation ( $\mathrm{Hg} 2+$ ) and Anion (S2-) Ions Based on CMS/AgNPs Composites," Polymers, vol. 12, 2020. 